Sasa Lukic ${ }^{\mathrm{a},}$, Gerdina Wilhelmina Busser ${ }^{\mathrm{a}}$, Siyuan Zhang, Jasper Menze, Martin Muhler, Christina Scheu and Markus Winterer

\title{
Nanocrystalline Ga-Zn Oxynitride Materials: Minimized Defect Density for Improved Photocatalytic Activity?
}

https://doi.org/10.1515/zpch-2019-1432

Received April 3, 2019; accepted November 4, 2019

Abstract: We present an alternative synthesis strategy for developing nanocrystalline $\left(\mathrm{Ga}_{1-\mathrm{x}} \mathrm{Zn}_{\mathrm{x}}\right)\left(\mathrm{N}_{1-\mathrm{x}} \mathrm{O}_{\mathrm{x}}\right)$ semiconductors known to be very efficient photoabsorbers. In a first step we produce mixtures of highly crystalline $\beta$ - $\mathrm{Ga}_{2} \mathrm{O}_{3}$ and wurtzite-type $\mathrm{ZnO}$ nanoparticles by chemical vapor synthesis. $\left(\mathrm{Ga}_{1-\mathrm{x}} \mathrm{Zn}_{\mathrm{x}}\right)\left(\mathrm{N}_{1-\mathrm{x}} \mathrm{O}_{\mathrm{x}}\right)$ nanoparticles of wurtzite structure are then formed by reaction of these precursor materials with ammonia. Microstructure as well as composition (zinc loss) changes with nitridation time: band gap energy, crystallite size and crystallinity increase, while defect density decreases with increasing nitridation time. Crystallite growth results in a corresponding decrease in specific surface area. In the UV regime photocatalytic activity for overall water splitting can be monitored for samples both before and after nitridation. We find a significantly lower photocatalytic activity in the nitrided samples, even though the crystallinity is significantly higher and the defect density is significantly lower after nitridation. Both properties should have led to a lower probability for charge carrier recombination, and, consequently, to a higher photocatalytic activity.

Keywords: chemical vapor synthesis; $\left(\mathrm{Ga}_{1-\mathrm{x}} \mathrm{Zn}_{\mathrm{x}}\right)\left(\mathrm{N}_{1-\mathrm{x}} \mathrm{O}_{\mathrm{x}}\right)$; nanoparticles; overall water splitting.

\footnotetext{
${ }^{a}$ Sasa Lukic and Gerdina Wilhelmina Busser: These authors contributed equally to this work. *Corresponding author: Sasa Lukic, Nanoparticle Process Technology (NPPT) and Center for Nanointegration Duisburg-Essen (CENIDE), University of Duisburg-Essen, 47057 Duisburg, Germany, e-mail: sasa.lukic@uni-due.de
}

Gerdina Wilhelmina Busser, Jasper Menze and Martin Muhler: Laboratory of Industrial Chemistry, Ruhr-University Bochum, 44780 Bochum, Germany

Siyuan Zhang and Christina Scheu: Max-Planck-Institut für Eisenforschung GmbH, 40237 Düsseldorf, Germany

Markus Winterer: Nanoparticle Process Technology (NPPT) and Center for Nanointegration Duisburg-Essen (CENIDE), University of Duisburg-Essen, 47057 Duisburg, Germany 


\section{Introduction}

The development of semiconductors that split water photocatalytically under visible-light irradiation is a promising path to the efficient conversion of solar energy. Various oxides with $\mathrm{d}^{0}$ and $\mathrm{d}^{10}$ electron configuration possess such photocatalytic activity, but suffer from poor oxygen and hydrogen evolution or work only in the ultraviolet regime [1]. Many photocatalysts have been proposed as potential candidates, and oxynitrides were found to function as stable photocatalysts for water reduction and oxidation under visible irradiation. However, most of them are active only for a half reaction in the presence of a sacrificial agent [2]. The logical first step in rational materials design is to prepare a material able to absorb photons and generate electron-hole pairs with optimized band gap energy and band edge positions. In addition to photon absorption, effective charge separation and transport to the active sites need to be efficient, demanding highly crystalline materials without defects and short diffusion paths to the surface provided by nanosized particles. Generally, heterogeneous photocatalysis requires high specific surface area, which is also provided by the nanosized particles, but the surface is then also the dominant defect. Only two oxynitrides have been found to be active for full overall water splitting: $\left(\mathrm{Zn}_{1+\mathrm{x}} \mathrm{Ge}\right)\left(\mathrm{N}_{2} \mathrm{O}_{\mathrm{x}}\right)$ [3] and $\left(\mathrm{Ga}_{1-\mathrm{x}} \mathrm{Zn}_{\mathrm{x}}\right)\left(\mathrm{N}_{1-\mathrm{x}} \mathrm{O}_{\mathrm{x}}\right)$ with $\mathrm{RhO}_{2}$ and $\mathrm{Cr}$ as cocatalyst first prepared by Maeda et al. $[4,5]$. It was demonstrated by Ohno et al. that the overall water splitting rate of these oxynitrides is stable for 3 months [5]. Crystallinity, surface area and composition of $\left(\mathrm{Ga}_{1-\mathrm{x}} \mathrm{Zn}_{\mathrm{x}}\right)\left(\mathrm{N}_{1-\mathrm{x}} \mathrm{O}_{\mathrm{x}}\right)$ solid solutions are found to strongly depend on the morphology of $\mathrm{ZnO}$ particles, but are relatively insensitive to $\mathrm{Ga}_{2} \mathrm{O}_{3}$, which underlines the importance of the appropriate selection of the precursor materials [6-8]. For efficient solar energy conversion a photocatalyst that absorbs light with wavelengths longer than $600 \mathrm{~nm}$ is highly desirable [9], requiring a semiconducting material with a band gap energy smaller than $2 \mathrm{eV}$. The concentration of $\mathrm{Zn}^{2+}$ in these oxynitrides is a key factor determining the band gap. Density functional theory computations for $\left(\mathrm{Ga}_{1-\mathrm{x}} \mathrm{Zn}_{\mathrm{x}}\right)\left(\mathrm{N}_{1-\mathrm{x}} \mathrm{O}_{\mathrm{x}}\right)$ show that the band gap energy decreases to $2.29 \mathrm{eV}$, when the ratio of $\mathrm{Zn} /(\mathrm{Zn}+\mathrm{Ga})$ reaches 0.525 [10]. A further increase of the $\mathrm{Zn}$ content lowers the band gap energy to the desirable $2 \mathrm{eV}$. It has been observed that nitridation under a flow of ammonia leads to a huge loss of $\mathrm{Zn}$ due to its volatilization [8,11]. Chen et al. reported in their review that until now the maximum $\mathrm{Zn} /(\mathrm{Zn}+\mathrm{Ga})$ ratio obtained in thermal nitridation processes by using $\mathrm{NH}_{3}$ as a reaction gas is below 0.33 and that new synthesis strategies are required [12].

In this work we exploit the advantages of chemical vapor synthesis (CVS) to directly obtain intimate mixtures of nanocrystalline $\beta-\mathrm{Ga}_{2} \mathrm{O}_{3}$ and $\mathrm{ZnO}$. 
Homogeneous blends are difficult if impossible to obtain by mechanical mixing of (dry) powders consisting of nanoparticles. Nanoparticles dispersed in gases as in CVS provide an alternative facile route: by adjusting process parameters such as temperature, system pressure and precursor evaporation rate, we are able to tune the characteristics of the materials, such as specific surface area, crystallinity and particle size, as reported for pure $\beta-\mathrm{Ga}_{2} \mathrm{O}_{3}$ [13]. CVS powders, compared to solid solution materials made by solid-state phase synthesis, possess much higher crystallinity and higher surface to volume ratio, which is known to be beneficial for the surface chemical reactions in heterogeneous photocatalysis. Starting materials and further processing influence the properties of the final products and their photocatalytic activities. We optimize the CVS process aiming for improved photocatalytic properties. Without co-catalysts, semiconductor particles exhibit low photocatalytic activity. Nakibli et al. reported on the importance of co-catalyst size on charge transfer and photocatalytic activity [14]. In the UV regime we are able to compare overall water splitting activity both before and after nitridation. The goal of the work reported here is to find alternative synthesis routes and a deeper understanding of how the nitridation process influences the properties of CVS nanoparticles and their photocatalytic activities.

\section{Experimental}

\subsection{Starting materials}

Solid gallium(III)acetylacetonate (Ga(acac) 3 , STREM, 99.99\%) in a combination with liquid diethylzinc (DEZ, STREM, min. 95\%) are used as precursors for chemical vapor synthesis of $\beta-\mathrm{Ga}_{2} \mathrm{O}_{3}-\mathrm{ZnO}$ nanoparticle mixtures. As reaction and carrier gas, oxygen (Air Liquide, Purity 5.1, 99.9991\%) and helium (Air Liquide, Alfagaz 1, 99.999\%), are used for the oxides in this first step. Ammonia (Air Liquide, 99.999\%) is used for the ammonolysis of the as prepared oxide nanoparticles in the second step to obtain the desired Ga-Zn oxynitride nanoparticles.

\subsection{Synthesis and nitridation}

The CVS reactor is a modular system consisting of a precursor delivery zone, a reaction zone, a thermophoretic collector for nanoparticles and a vacuum pump (schematically shown in Figure 1). The process parameters used $\left(T_{1}=1200{ }^{\circ} \mathrm{C}\right.$, 


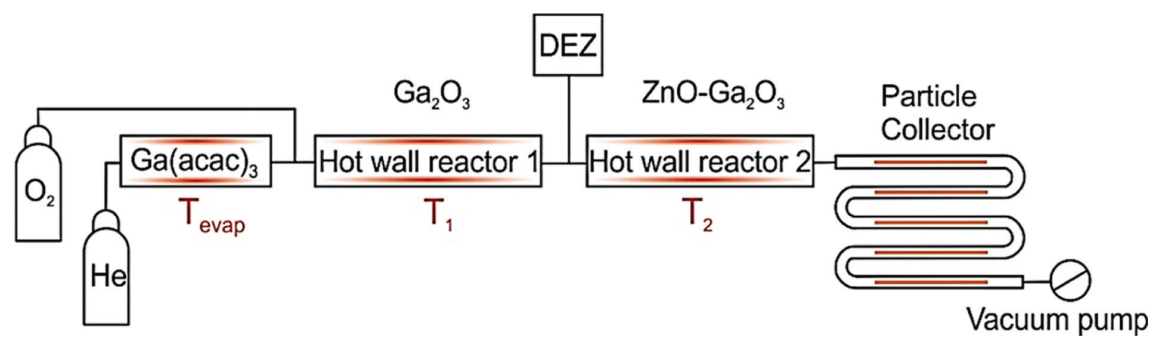

Fig. 1: CVS system used to synthesize mixtures of $\mathrm{Ga}_{2} \mathrm{O}_{3}-\mathrm{ZnO}$ nanoparticles.

$p=300$ mbar, $T_{\text {evap }}=196^{\circ} \mathrm{C}$ and mass flows of $\mathrm{O}_{2}$ and $\mathrm{He}$, set to 1700 and $600 \mathrm{sccm}$, respectively) are based on our earlier investigation [13]. Helium, as a carrier gas, is supplied through the $\mathrm{Ga}(\mathrm{acac})_{3}$ supply zone and oxygen, as a reaction gas, is added just before the hot wall reactor to prevent preliminary oxidation. After generation of $\mathrm{Ga}_{2} \mathrm{O}_{3}$ nanoparticles from $\mathrm{Ga}(\mathrm{acac})_{3}$ in the first reactor, $\mathrm{DEZ}$ is added before the second reactor with the aim of homogeneously mixing $\mathrm{Ga}_{2} \mathrm{O}_{3}$ with $\mathrm{ZnO}$ nanoparticles already in the gas stream. Helium, with a mass flow of 50 sccm is passed through the bubbler containing DEZ, while the temperature of the bubbler is kept constant at $20^{\circ} \mathrm{C}$. By changing the temperature of the second hot wall reactor, $T_{2}\left(300-1000{ }^{\circ} \mathrm{C}\right)$, it is possible to control the $\mathrm{Zn} /(\mathrm{Zn}+\mathrm{Ga})$ ratio, as well as particle size and crystallinity in the product of the CVS process consisting of $\mathrm{Ga}_{2} \mathrm{O}_{3}-\mathrm{ZnO}$ nanoparticle mixtures. These powders are then nitrided in a tubular furnace in an $\mathrm{Al}_{2} \mathrm{O}_{3}$ reaction tube with an inner diameter of $18 \mathrm{~mm}$ at a heating rate of $7{ }^{\circ} \mathrm{C} \mathrm{min}{ }^{-1}$ under ammonia gas flow of $50 \mathrm{sccm}$ at atmospheric pressure. Heating to $850{ }^{\circ} \mathrm{C}$ and cooling to room temperature is carried out under a nitrogen gas flow of $300 \mathrm{sccm}$.

\subsection{Characterization}

The crystal structure of the samples synthesized by CVS in the first step and nitrided in the second step are examined by means of X-ray diffraction (XRD) using a PANalytical X-ray diffractometer (X'Pert PRO) equipped with an X'Celerator detector with Ni-filtered $\mathrm{Cu} \mathrm{K \alpha}(1.54056 \AA$ ) radiation produced at $40 \mathrm{kV}$ and $40 \mathrm{~mA}$ with step size of $0.0167^{\circ}$, a scan speed of $0.006^{\circ} / \mathrm{s}$ and a time per step of 347.35 s. Rietveld refinement is performed using the MAUD software providing quantitative information about phase composition, crystal structure and microstructure (lattice constants, atomic positions, crystallite size, microstrain 
and twin and intrinsic fault probabilities). Measurements are performed in BraggBrentano geometry using a zero background holder $(\mathrm{ZBH})$ with and without powder which enables the removal of the background of the $\mathrm{ZBH}$ from the sample signal. Additionally, a NIST $\mathrm{LaB}_{6}$ standard powder was measured using identical parameters as described above to obtain the instrumental broadening profile. The corresponding instrumental parameters are fixed in the Rietveld refinement of our samples and only the parameters describing the crystal and microstructure of the samples are fitted. Quantitative information regarding microstructure is achieved by a combination of the Popa model for size and strain and the Warren theory for planar defects $[15,16]$ implemented in the MAUD code. The degree of crystallinity, $\Gamma$, is estimated from the ratio of the coherently scattered intensity to the total scattered intensity in the X-ray diffraction data (after substracting the background due to the $\mathrm{ZBH})$ :

$$
\Gamma=\frac{\int A \mathrm{~d} \theta}{\int(A+B) \mathrm{d} \theta}
$$

where $A$ is the intensity due to coherent scattering, $B$ is the background signal due to incoherent scattering and $\theta$ is scattering angle. This relative measure for crystallinity is applied to all samples identically providing consistent information about the trend as a function of synthesis/process parameters. A Quantachrome Autosorb 1C instrument is used to obtain the specific surface area (SSA) based on nitrogen physisorption at $77 \mathrm{~K}$ and the Brunauer-Emmett-Teller (BET) equation. The samples are degassed at a temperature of $120^{\circ} \mathrm{C}$ under vacuum for about $10 \mathrm{~h}$, nitrogen is used as a backfill gas prior to nitrogen adsorption. Size, morphology, crystal structure, microstructure and composition of the nanoparticles are studied by electron microscopy using a scanning transmission electron microscope (STEM, TITAN Themis microscope) and a scanning electron microscope (HRSEM, JEOL JSM 7500F) complemented by energy dispersive X-ray spectroscopy (EDS). Corresponding samples are prepared by dispersing $1 \mathrm{mg}$ of powder in $10 \mathrm{~mL}$ of isopropanol in an ultrasonic bath for $15 \mathrm{~min}$ and subsequent drop casting on a carbon film on 300 mesh TEM copper grids. A Perkin Elmer Lambda 650 spectrophotometer and a Harrick Praying Mantis diffuse reflectance accessory are used to measure UV/Vis diffuse reflectance spectra recorded under ambient conditions in a range from 800 to $200 \mathrm{~nm}$ with resolution of $1 \mathrm{~nm}$ and integration time of $0.4 \mathrm{~s}$. For this $25 \mathrm{mg}$ of CVS powder is diluted in $500 \mathrm{mg}$ of BaSO4, which is used as the $100 \%$ internal reflectance standard. Band gap energies of the CVS samples after nitridation are derived using the Kubelka-Munk function $[F(R \infty) h v]^{1 / 2}$ calculated from the reflectance spectra ( $R$ vs. $E$ ) and the Tauc plot. 


\subsection{Photocatalytic activity - overall water splitting}

The photodeposition/water splitting experiments are performed in a specially designed set-up, allowing continuous on-line detection of hydrogen, oxygen, and carbon dioxide as described previously [17]. A home-made quartz reactor with an inner irradiation-type light source is connected to a gas-dosing system equipped with a mass flow controller (Bronkhorst). In this configuration, the light source is surrounded by a quartz tube and positioned inside the liquid. Therefore, the complete light intensity is forced to pass through the liquid and losses due to scattering do not have to be considered. The inert carrier gas (nitrogen; flows adjustable from 0 to $75 \mathrm{~mL} \mathrm{~min}^{-1}$; typical flow: $50 \mathrm{~mL} \mathrm{~min}^{-1}$ ) is passed through the reactor using a Teflon inlet tube. In a typical experiment, the catalyst is suspended in $500 \mathrm{~mL}$ of deionized water. The suspension is degassed by flushing with nitrogen for $1 \mathrm{~h}$ and subsequently irradiated by using a mercury lamp (Peschl, Hg immersion lamp TQ, power adjustable from 0 to $700 \mathrm{~W}$, typical power applied: $500 \mathrm{~W}$; $\lambda=250-600 \mathrm{~nm}$ ) or a Xe lamp (Peschl, Xe immersion lamp TX, $150 \mathrm{~W}, \lambda=400-$ $800 \mathrm{~nm}$ ). On-line analysis of the evolving gas mixture is performed by using a three-channel analyser (Emerson) equipped with detectors for the determination of the concentration of hydrogen (thermal conductivity detector), oxygen (paramagnetic detector), and carbon dioxide (IR detector). The measured concentrations are recorded using a PC equipped with LabView software.

\section{Results and discussion}

\subsection{Chemical vapor synthesis}

$\mathrm{Ga}_{2} \mathrm{O}_{3}$ nanoparticles are synthesized from the solid precursor in the first hot wall reactor at optimized conditions and $\mathrm{ZnO}$ nanoparticles in the second wall reactor at temperatures of $300,400,500$ and $1000{ }^{\circ} \mathrm{C}$. The nanoparticles are homogeneously mixed directly in the gas phase as it is evident from the distribution of $\mathrm{Ga}$ and $\mathrm{Zn}$ in the powder (Figure 2).

Results regarding ratios of $\mathrm{Zn} /(\mathrm{Zn}+\mathrm{Ga})$ obtained from EDS and from the phase composition according to Rietveld refinement of XRD data are compared in Figure 3. Here, XRD provides information only about the crystalline part of the material. At lower temperatures in the second hot wall reactor XRD and EDS results differ significantly probably due to the presence of organic residues (e.g. partially decomposed precursor) and material of low crystallinity in the collected powder. At higher temperatures $\left(1000^{\circ} \mathrm{C}\right)$ with increased crystallinity XRD and EDS results are in good agreement. Transport of charge carriers to the surface of 


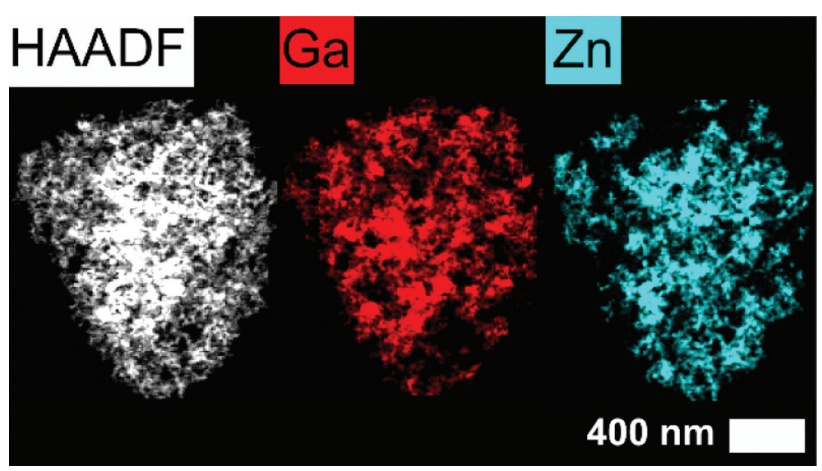

Fig. 2: High-angle annular dark-field (HAADF)-STEM micrograph and the EDS elemental maps of $\mathrm{Ga}$ and $\mathrm{Zn}$ of $\mathrm{Ga}_{2} \mathrm{O}_{3}-\mathrm{ZnO}$ powders.
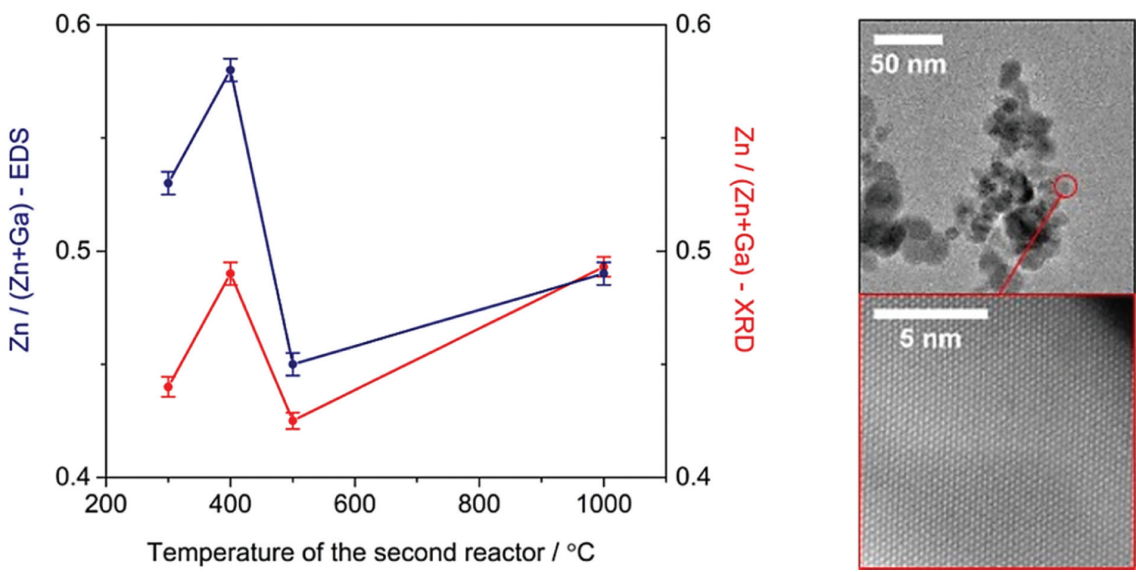

Fig. 3: $\mathrm{Zn} /(\mathrm{Zn}+\mathrm{Ga})$ ratios obtained from EDS - blue and computed from phase fractions extracted from Rietveld refinement of XRD data - red (left) and TEM images of the highly crystalline $\mathrm{Ga}_{2} \mathrm{O}_{3}-\mathrm{ZnO}$ nanoparticle mixture synthesized at $T_{1}=1200{ }^{\circ} \mathrm{C}$ and $T_{2}=1000{ }^{\circ} \mathrm{C}$ (right).

the semiconductor nanoparticles is improved by high crystallinity, respectively minimum defect density since the probability for charge carrier recombination is lowered. Therefore, we focus on the $\mathrm{Ga}_{2} \mathrm{O}_{3}-\mathrm{ZnO}$ mixture synthesized at $T_{1}=1200{ }^{\circ} \mathrm{C}$ (first hot wall reactor) and $T_{2}=1000{ }^{\circ} \mathrm{C}$ (second hot wall reactor), respectively.

\subsection{Nitridation of CVS powders and characterization}

The $\mathrm{Ga}_{2} \mathrm{O}_{3}-\mathrm{ZnO}$ sample synthesized at high temperatures $\left(T_{1}=1200{ }^{\circ} \mathrm{C}\right.$ and $\left.T_{2}=1000{ }^{\circ} \mathrm{C}\right)$ with a ratio $\mathrm{Zn} /(\mathrm{Zn}+\mathrm{Ga})$ of 0.49 is nitrided at $850{ }^{\circ} \mathrm{C}$ as described 
above to obtain the desired $\left(\mathrm{Ga}_{1-\mathrm{x}} \mathrm{Zn}_{\mathrm{x}}\right)\left(\mathrm{N}_{1-\mathrm{x}} \mathrm{O}_{\mathrm{x}}\right)$ phase. The influence of the nitridation time on the microstructure and chemical composition is investigated. The $\mathrm{Zn} /(\mathrm{Zn}+\mathrm{Ga})$ ratio as well as the band gap energy as a function of nitridation time are presented in Figure 4. The decrease of the $\mathrm{Zn}$ content, which is directly observed as deposit on the inner wall of the nitridation tube, leads to an increase of the band gap energy from $2.4 \mathrm{eV}$ to $2.6 \mathrm{eV}$ and may be due to the now decreased repulsion of $\mathrm{Zn} 3 \mathrm{~d}$ and N 2p orbitals [18]. This shifts the valence band maximum downward without affecting the conduction band minimum. A lower electron occupation in the upper valence band reduces its maximum resulting in expanding of the band gap [19]. The band gap of a semiconductor is either direct or indirect. In Figure $5 \mathrm{UV} /$ Vis spectral data of materials before nitridation $\left(\mathrm{Ga}_{2} \mathrm{O}_{3}-\right.$ $\mathrm{ZnO})$ and after nitridation for $5 \mathrm{~h}\left(\mathrm{Ga}_{1-\mathrm{x}} \mathrm{Zn}_{\mathrm{x}}\right)\left(\mathrm{N}_{1-\mathrm{x}} \mathrm{O}_{\mathrm{x}}\right)$ are compared. The oxide mixture displays direct band gaps (DBG) of $3.3 \mathrm{eV}$ for $\mathrm{ZnO}$ and $4.8 \mathrm{eV}$ for $\mathrm{Ga}_{2} \mathrm{O}_{3}$,
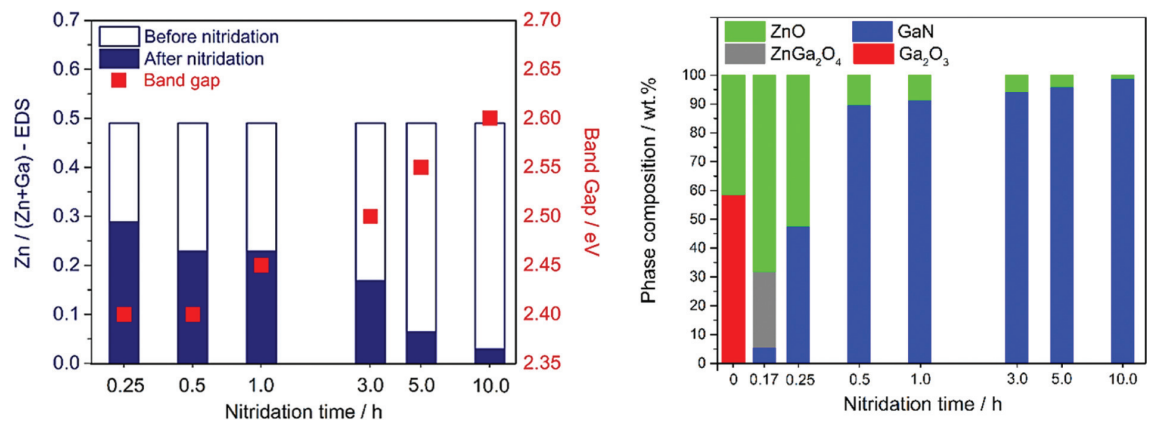

Fig. 4: Concentration of $\mathrm{Zn}$ and the band gap energy (left) and phase composition starting from the mixture of $\mathrm{Ga}_{2} \mathrm{O}_{3}-\mathrm{ZnO}$ (58.6: 41.4 wt.\%) (right) as a function of the nitridation time.
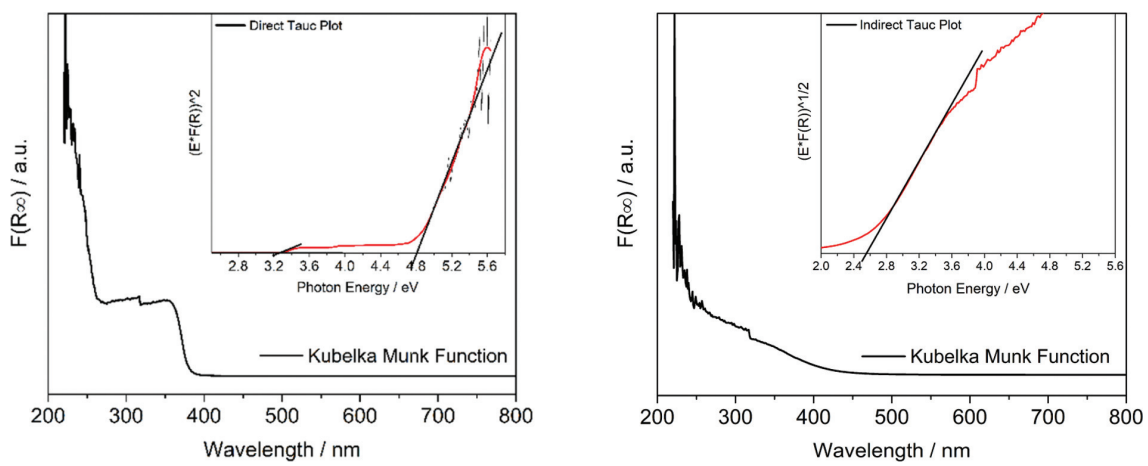

Fig. 5: UV/Vis absorption spectra of: $\mathrm{Ga}_{2} \mathrm{O}_{3}-\mathrm{ZnO}$ mixture (left) and $\left(\mathrm{Ga}_{1-\mathrm{x}} \mathrm{Zn}_{\mathrm{x}}\right)\left(\mathrm{N}_{1-x} \mathrm{O}_{\mathrm{x}}\right)$ after nitridation for $5 \mathrm{~h}$ (right). 
while for the nitrided sample an indirect band gap (IBG) of $2.55 \mathrm{eV}$ is observed. The lowest energy state in the conduction band and the highest energy state in the valence band are characterized by a specific crystal momentum ( $k$-vector). If those $k$-vectors are identical, the momentum of electrons and holes is the same and an electron can directly be excited by a photon when synthesized nanoparticles absorb the sunlight. If the vectors differ, an electron must pass through an intermediate state and transfer momentum to the crystal lattice. The efficiency factor of charge separation of DBG semiconductors is higher compared to IBG semiconductors. All nitrided samples have an IBG. Hence, it is expected that oxide mixtures may be more active than nitrided samples but they suffer from the larger bandgap as described above.

With increasing nitridation time from $0.5 \mathrm{~h}$ to $10 \mathrm{~h}$, the mixture of $\mathrm{ZnO}-\mathrm{Ga}_{2} \mathrm{O}_{3}$ (originally of wurtzite and monoclinic crystal structure) is transformed into the crystalline wurtzite phase of the oxynitride. In Figure 6a X-ray diffraction patterns
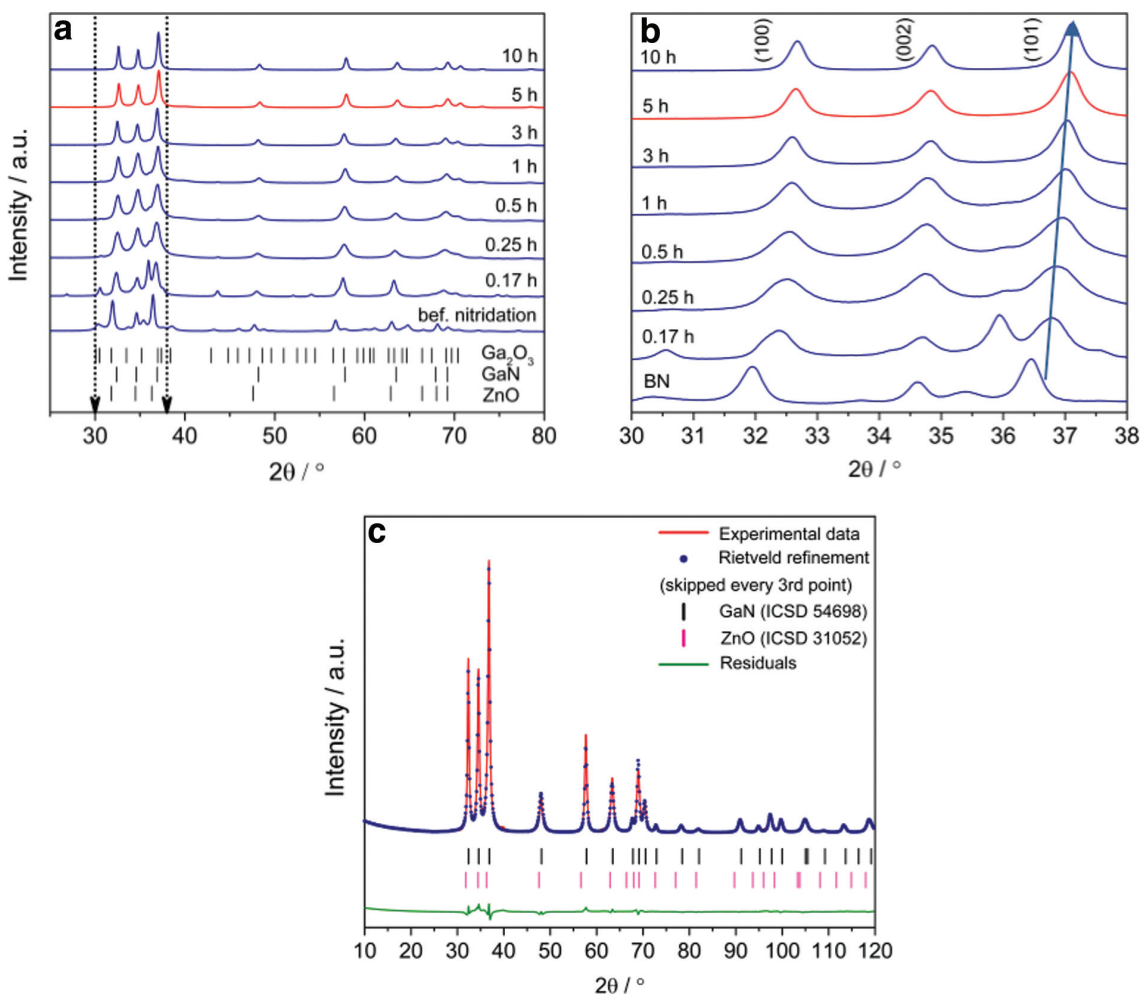

Fig. 6: (a) Overview of the X-ray diffractograms of the samples starting from the $\mathrm{Ga}_{2} \mathrm{O}_{3}-\mathrm{ZnO}$ mixture as a function of the nitridation time and (b) diffracted intensities between $30^{\circ}$ and $38^{\circ}$ $2 \theta$, (c) XRD pattern of the sample nitrided for $5 \mathrm{~h}$ fitted by Rietveld refinement using MAUD. 
as a function of nitridation time are normalized to the individual maximum intensity for graphical clarity. In the nitridation process the oxygen atoms are partially replaced by nitrogen atoms. The $\mathrm{Zn}-\mathrm{O}$ bond is weaker $(1.65 \mathrm{eV})$ compared with $\mathrm{Ga}-\mathrm{O}(3.66 \mathrm{eV})$ and, therefore, it is easier to break, which explains the huge loss of $\mathrm{Zn}$ during the nitridation process and the presences of $\mathrm{GaN}$ as the dominant constituent after $10 \mathrm{~h}$. Figure $6 \mathrm{~b}$ displays X-ray diffraction patterns between $30^{\circ}$ and $38^{\circ}$ to demonstrate the shift of the Bragg reflections due to transformation of the $\mathrm{Ga}_{2} \mathrm{O}_{3}-\mathrm{ZnO}$ mixture during nitridation, as previously described by Domen [20]. A typical Rietveld refinement is shown in the Figure $6 \mathrm{c}$ for the sample nitrided for $5 \mathrm{~h}$ which showed the highest photocatalytic activity. The computed model agrees very well with the experimental data $\left(R_{w p}=1.6 \%\right)$. This method allows the extraction phase composition, crystal and microstructure. The influence of the nitridation time on the phase composition starting from the mixture of $\mathrm{Ga}_{2} \mathrm{O}_{3}-$ $\mathrm{ZnO}$ (58.6: $41.4 \mathrm{wt} . \%)$ is displayed in Figure 4. After $0.17 \mathrm{~h}(10 \mathrm{~min})$ of nitridation the monoclinic structure of $\mathrm{Ga}_{2} \mathrm{O}_{3}$ is no longer observed due to the formation of spinel-structure $\mathrm{ZnGa}_{2} \mathrm{O}_{4}$ (26.4 wt.\%) with excess amount of $\mathrm{ZnO}$ (68 wt.\%) and $\mathrm{GaN}$ (5.6 wt.\%). With increasing nitridation time the quantity of the wurtzite GaN phase is increasing as a result of the $\mathrm{Zn}$ loss.

The crystallite size increases from about $9 \mathrm{~nm}$ to $30 \mathrm{~nm}$ due to particle growth and sintering corresponding to a decrease in the specific surface area from about $46 \mathrm{~m}^{2} / \mathrm{g}$ to $14.7 \mathrm{~m}^{2} / \mathrm{g}$ (Figure $7 \mathrm{a}$ ). However, these surface areas are still considerably large compared with those of materials obtained through the solid-state route reported by Maeda and coworkers [6-8]. This probably explains why the $\mathrm{Zn}$ loss is also more pronounced. As an example, a nitridation time of $5 \mathrm{~h}$ results in a material with a $\mathrm{Zn} /(\mathrm{Zn}+\mathrm{Ga})$ ratio of 0.06 , whereas Maeda and coworkers report a $\mathrm{Zn} /(\mathrm{Zn}+\mathrm{Ga})$ ratio of 0.22 . The broadening of the Bragg reflections contains quantitative microstructural information through size and microstrain contributions, which can be extracted and discriminated by Rietveld refinement. Corresponding results are compiled in Figure 7. Microstrain is a result of local variation of lattice constants due to defects [21]. Defects may act as traps for charge carriers, where recombination of electron-hole pairs is likely thus deteriorating charge carrier transport to the surface and lowering photocatalytic activity. The microstrain of the nitrided CVS samples decreases with increasing nitridation time, while the degree of crystallinity increases (Figure 7b). Twin fault probabilities and intrinsic (stacking) fault probabilities are decreasing as well with nitridation time (Figure 7c). The lattice constants of the $\left(\mathrm{Ga}_{1-\mathrm{x}} \mathrm{Zn}_{\mathrm{x}}\right)\left(\mathrm{N}_{1-\mathrm{x}} \mathrm{O}_{\mathrm{x}}\right)$ phase, which crystallizes in the wurtzite crystal structure of $\mathrm{GaN}$ (space group $\mathrm{P}_{3} \mathrm{mc}$ ), are decreasing with increasing nitridation time (Figure 7d). Compared with GaN the lattice constants are larger because of the incorporation of $\mathrm{Zn}^{2+}$ (ionic radius of $0.74 \AA$ ), 

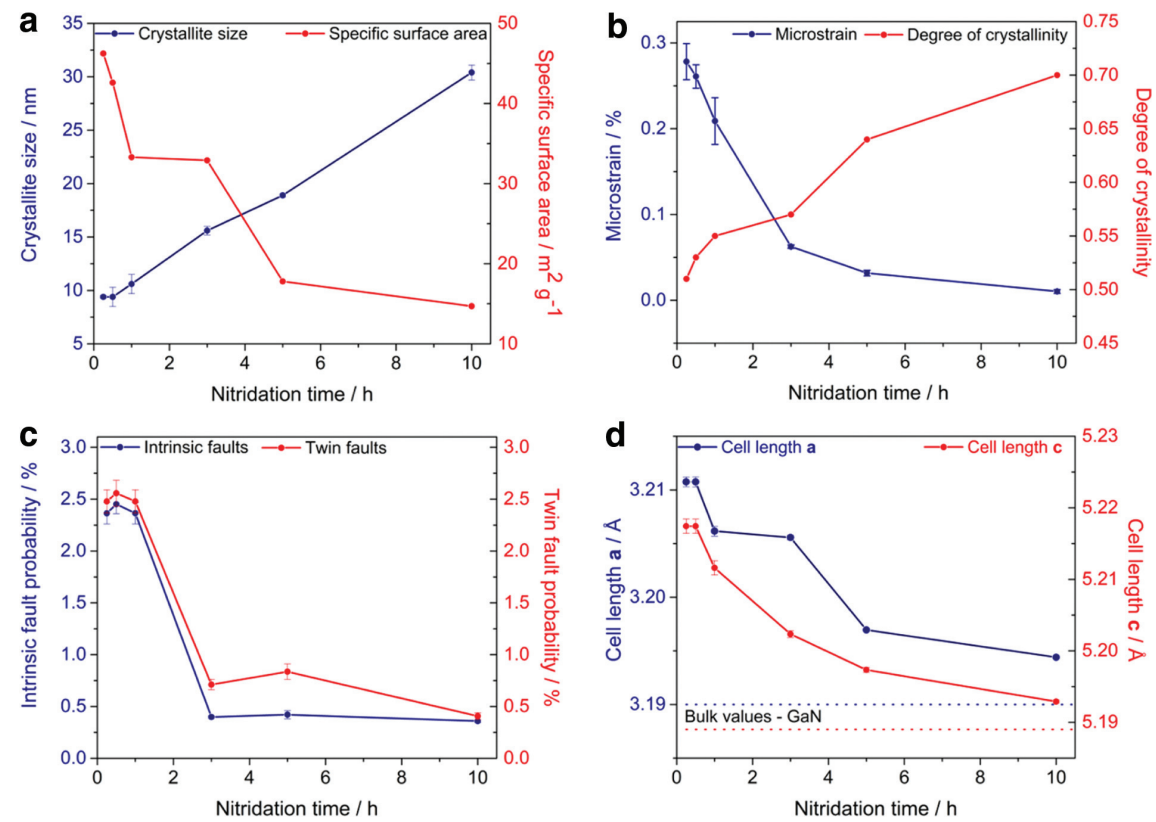

Fig. 7: Influence of nitridation time on (a) crystallite size and specific surface area, (b) microstrain and crystallinity, (c) intrinsic (stacking) and twin fault probabilities and (d) lattice parameters.

which is larger than $\mathrm{Ga}^{3+}$ (ionic radius of $0.61 \AA$ ) [22]. After $10 \mathrm{~h}$ of nitridation the lattice parameters are closest to the bulk values reported for bulk GaN as a result of the huge $\mathrm{Zn}^{2+}$ loss. Additionally, the remaining deviation from the bulk lattice constants could be also due to the nanoscaled nature of the particles [23]. The particle characteristics are compiled in Table 1. Obviously, with increasing nitridation time all indicators for defect density decrease. Therefore, one expects a decrease in the recombination rate of charge carriers and improved photocatalytic activity. However, the specific surface area also decreases and visible light absorption also originates from $\mathrm{Zn}$ and $\mathrm{O}$ impurity states as reported previously by Hirai et al. [25]. Therefore, the nitrided samples might be active only when irradiated with UV light with lower photocatalytic activity compared with the parent oxide mixture.

In Figure 8, atomic resolution STEM images show the wurtzite crystal structure of the nanoparticles and their high crystallinity from the core to the surface. Stacking faults of the wurtzite structure can be observed along the [11-20] zone 


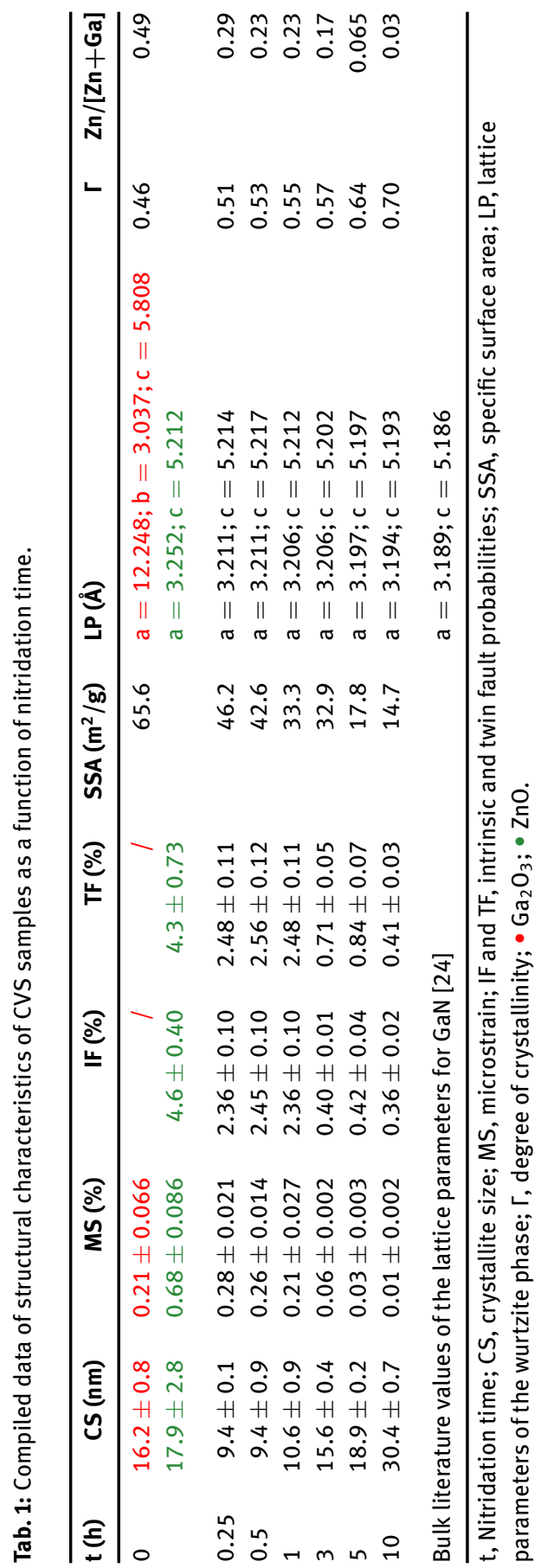




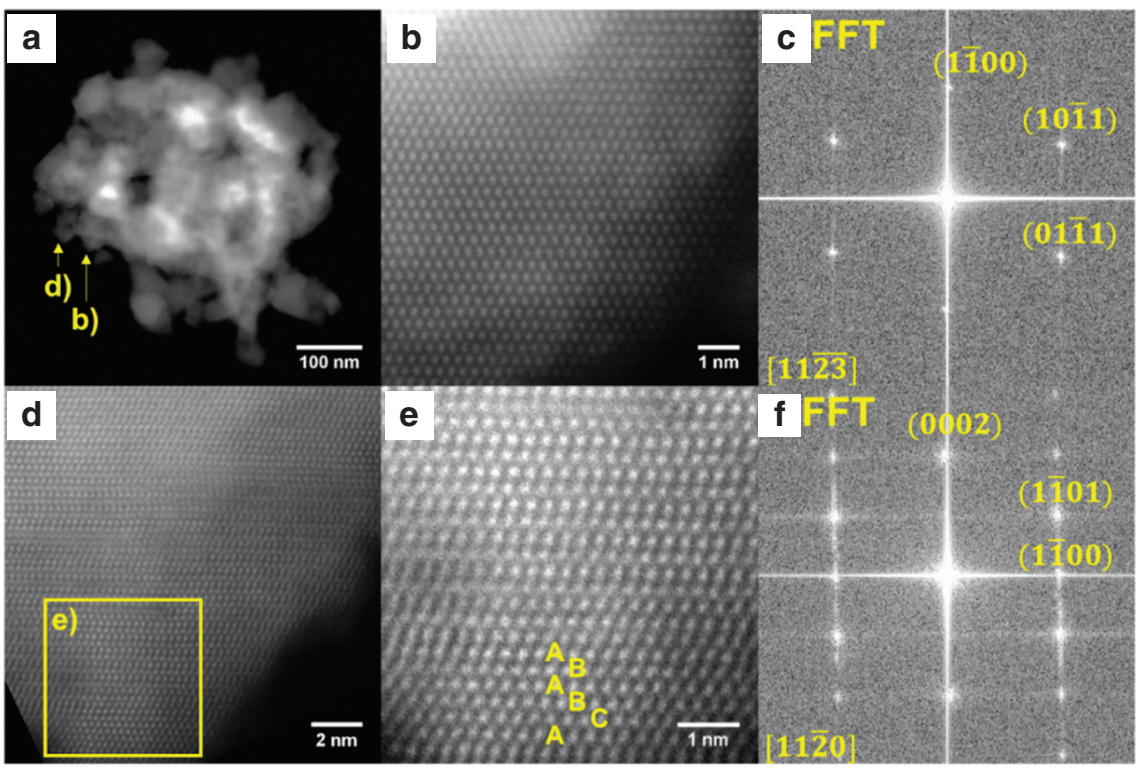

Fig. 8: STEM images of nanoparticles after nitridation (a) and the atomic resolution micrographs along [11-2-3] (b) and [11-20] (d,e) zone axis with their corresponding fast Fourier transfer (FFT) patterns. A stacking fault (layer $\mathrm{C}$ ) is labelled in the hexagonal ABAB... stacking along the (0002) plane (e). (c,f) Display fast Fourier transforms (FFT) of the images (b) and (e), respectively.

axis, and we show an example in Figure 8e. This validates the XRD peak fitting using stacking faults, whose density is plotted in Figure 7c.

\subsection{Photocatalytic overall water splitting}

$\left(\mathrm{Ga}_{1-\mathrm{x}} \mathrm{Zn}_{\mathrm{x}}\right)\left(\mathrm{N}_{1-\mathrm{x}} \mathrm{O}_{\mathrm{x}}\right)$ loaded with Rh- and Cr-containing cocatalysts are often proposed as promising materials as a single-phase photocatalyst for water splitting under visible light irradiation. Quantum yields up to $2.5 \%$ are reported using light with wavelengths between 400 and $500 \mathrm{~nm}$ and activities up to $462.9 \mu \mathrm{mol} \mathrm{H} \mathrm{H}_{\mathrm{cat}}{ }^{-1} \mathrm{~h}^{-1}$ and $105.7 \mu \mathrm{mol} \mathrm{O} \mathrm{g}_{\mathrm{cat}}{ }^{-1} \mathrm{~h}^{-1}$, but also quantum yields of $0.16 \%$ at $400-500 \mathrm{~nm}$ [26]. The application of $\mathrm{Rh}$ and $\mathrm{Cr}$ as cocatalysts has been elaborately discussed by Maeda et al. [27, 28]. Therefore, we selected these materials as cocatalysts. Initially, we used a mercury light source emitting light with wavelengths between 250 and $600 \mathrm{~nm}$. This allows us to compare the CVS-prepared oxynitrides to the reference oxide mixture with a wide band gap (CVS-prepared $\mathrm{Ga}_{2} \mathrm{O}_{3}-\mathrm{ZnO}$ ). 


\subsubsection{In situ photo-deposition of the co-catalysts $\mathrm{Cr}$ and $\mathrm{Rh}$ on CVS prepared $\mathrm{Ga}_{2} \mathrm{O}_{3}-\mathrm{ZnO}$}

For commercial $\mathrm{Ga}_{2} \mathrm{O}_{3}$, optimum loadings of $0.1 \mathrm{wt} . \% \mathrm{Cr}$ and $0.1 \mathrm{wt} . \% \mathrm{Rh}$ were determined previously by stepwise in-situ photodeposition in $\mathrm{H}_{2} \mathrm{O} / \mathrm{MeOH}$ [17] as well as the optimum order of addition (first $\mathrm{Cr}$, then $\mathrm{Rh}$ ). In a first experiment, the in situ photodeposition of $\mathrm{Cr}$ and $\mathrm{Rh}$ in water (i.e. without the typical sacrificial agent $\mathrm{MeOH}$ ) is demonstrated with a mixture of CVS-prepared $\mathrm{Ga}_{2} \mathrm{O}_{3}-\mathrm{ZnO}$ as a reference. For that purpose, $150 \mathrm{mg}$ of the CVS-prepared oxide mixture is suspended in a mixture of water $(500 \mathrm{~mL})$ together with a small amount of a solution containing $\mathrm{K}_{2} \mathrm{CrO}_{4}(5.8 \mathrm{mM} ; 0.45 \mathrm{~mL})$ and flushed with nitrogen for $1 \mathrm{~h}$. This procedure is sufficient to achieve effective degassing as demonstrated by the measured oxygen concentration, which reached zero in that time interval. The amount is sufficient to lead to a loading of $0.1 \mathrm{wt} \% \mathrm{Cr}$ after photodeposition. After degassing, storing the measured data is started, and after $300 \mathrm{~s}$ the light source is switched on at $50 \%$ of the maximum intensity ( $\sim 500 \mathrm{~W})$. Subsequently, $\mathrm{H}_{2}$, $\mathrm{O}_{2}$ and $\mathrm{CO}_{2}$ evolution is monitored. Apart from a small amount of $\mathrm{CO}_{2}$, no other products are detected. $\mathrm{CO}_{2}$ results from the oxidation of carbonaceous residues present in the samples. After irradiating the solution for approximately $1 \mathrm{~h}$, the lamp is switched off. The resulting decrease of the signal occurred rapidly. When the concentration of $\mathrm{CO}_{2}$ reaches the detection limit, a second small amount of an aqueous solution containing $\mathrm{Na}_{3} \mathrm{RhCl}_{6} \cdot 3 \mathrm{H}_{2} \mathrm{O}(2.4 \mathrm{mM} ; 0.6 \mathrm{~mL})$ is added resulting in a nominal $\mathrm{Rh}$ loading of $0.1 \mathrm{wt} . \%$. After flushing out the residual air that is introduced together with the Rh-containing solution and thoroughly mixing for approximately $20 \mathrm{~min}$, the light is switched on again. Not only the $\mathrm{CO}_{2}$, but also the $\mathrm{H}_{2}$ concentration is observed to rise instantaneously. After irradiation for about $50 \mathrm{~min}$, the $\mathrm{CO}_{2}$ concentration has decreased sufficiently to allow the evolution of $\mathrm{O}_{2}$ to start. After $60 \mathrm{~min}$, the light is switched off again and another portion of Rh solution is added, the solution is degassed and the light is turned on again. This time, both $\mathrm{H}_{2}$ and $\mathrm{O}_{2}$ are detected simultaneously, while the $\mathrm{CO}_{2}$ concentration is negligible. The same procedure is repeated until $\mathrm{H}_{2}$ and $\mathrm{O}_{2}$ evolution do not change significantly anymore. This is the case at a loading of $0.6 \mathrm{wt} \% \mathrm{Rh}$. Finally, $20 \mathrm{~mL}$ of $\mathrm{MeOH}$ are added followed by switching the light on for about $30 \mathrm{~min}$. Results are displayed in Figure 9.

As pointed out before, chromia serves as an oxidation catalyst [29]. First, it catalyzes the oxidation of carbonaceous residues. After removal of the major part of these contaminations, the oxidation of $\mathrm{H}_{2} \mathrm{O}$ proceeds and thus $\mathrm{O}_{2}$ evolution is observed. The $\mathrm{H}_{2}$ evolution rate is enhanced after adding the second co-catalyst $\mathrm{Rh}$, which serves as a powerful $\mathrm{H}_{2}$ evolution catalyst. Thus, significant direct photocatalytic overall water splitting (POWS) is achieved by adding $\mathrm{Cr}$ and $\mathrm{Rh}$ as 


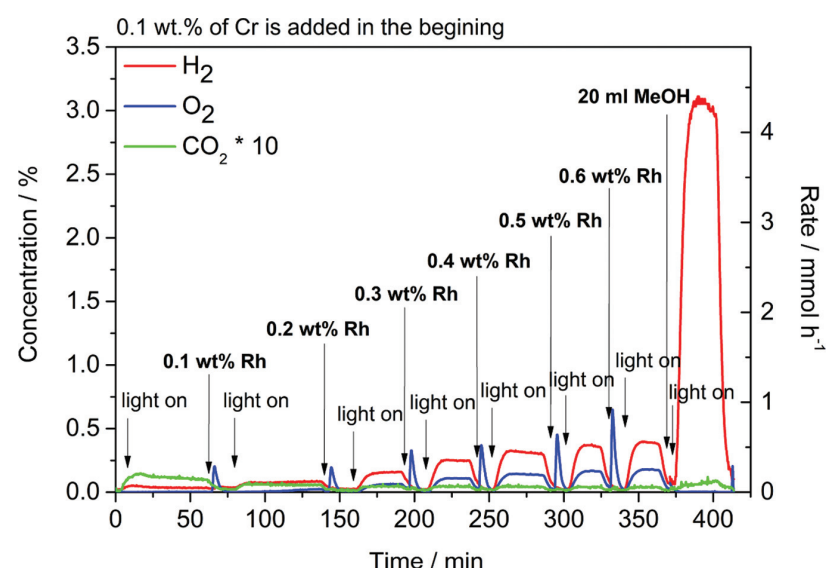

Fig. 9: Stepwise in-situ photodeposition/POWS of $\mathrm{Cr}$ and $\mathrm{Rh}$ in $\mathrm{H}_{2} \mathrm{O}$ on a CVS prepared $\mathrm{Ga}_{2} \mathrm{O}_{3}-\mathrm{ZnO}$ mixture before nitridation (150 mg).

co-catalysts. Interestingly, the optimum Rh loading is achieved at a loading which is twice as high as the optimum loading for commercial $\mathrm{Ga}_{2} \mathrm{O}_{3}$. This is probably due the presence of $\mathrm{ZnO}$ on the surface of the CVS-prepared material. The photocatalytic performance for methanol reforming, which is a relatively facile reaction compared with water splitting and often used as a hole scavenger, is also demonstrated by adding methanol. In summary, it can be concluded that the in situ photodeposition in $\mathrm{H}_{2} \mathrm{O}$ works quite well on the CVS-prepared $\mathrm{Ga}_{2} \mathrm{O}_{3}-\mathrm{ZnO}$ mixture and can be used as a tool to assess the suitability of the photoabsorber for POWS and photocatalytic methanol reforming.

\subsubsection{In situ photo-deposition of the co-catalyst $\mathrm{Cr}$ and $\mathrm{Rh}$ on $\left(\mathrm{Ga}_{1-\mathrm{x}} \mathrm{Zn}_{\mathrm{x}}\right)\left(\mathrm{N}_{1-\mathrm{x}} \mathrm{O}_{\mathrm{x}}\right)$}

For $\left(\mathrm{Ga}_{1-\mathrm{x}} \mathrm{Zn}_{\mathrm{x}}\right)\left(\mathrm{N}_{1-\mathrm{x}} \mathrm{O}_{\mathrm{x}}\right)$ prepared by performing the standard synthesis reported by Domen et al. (i.e. high-temperature solid-state synthesis (HTS) by nitridation of a physical mixture of $\mathrm{Ga}_{2} \mathrm{O}_{3}$ and $\mathrm{ZnO}$ with $\mathrm{NH}_{3}$ [19]), the optimum co-catalyst loadings were determined previously and amounted $0.1 \mathrm{wt} . \% \mathrm{Cr}$ and $0.3 \mathrm{wt} . \%$ $\mathrm{Rh}$ [17]. In order to determine the optimum Rh loading for the CVS samples, we stepwise added additional $\mathrm{Rh}$ to the system containing $0.1 \mathrm{wt} . \% \mathrm{Cr}$. The result with the sample after $5 \mathrm{~h}$ of nitridation is displayed in Figure 10. The activity increased until a Rh loading of $0.3 \mathrm{wt} . \%$ was reached. Further addition of Rh did not increase the hydrogen/oxygen evolution significantly. Thus, also for the CVS oxynitride sample, an optimum loading of $0.3 \mathrm{wt} . \% \mathrm{Rh}$ is established. Obviously, the optimum loading seems to be dictated mainly by the type of material, 


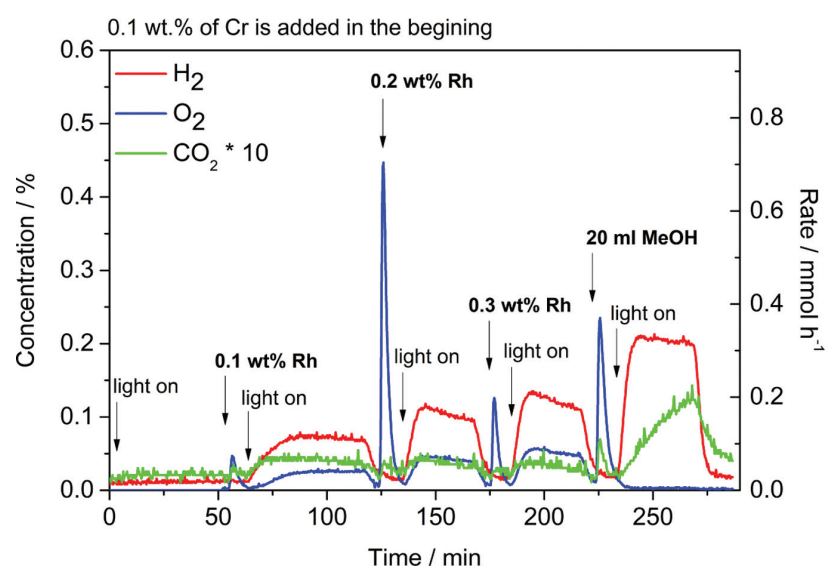

Fig. 10: Stepwise in-situ photodeposition/POWS of $\mathrm{Cr}$ and $\mathrm{Rh}$ in $\mathrm{H}_{2} \mathrm{O}$ on $\left(\mathrm{Ga}_{1-\mathrm{x}} \mathrm{Zn}_{\mathrm{x}}\right)\left(\mathrm{N}_{1-x} \mathrm{O}_{\mathrm{x}}\right)$ after nitridation for $5 \mathrm{~h}(\mathrm{x}=0.065)(150 \mathrm{mg})$.

whereas the synthesis route plays a minor role. Kudo and Miseki [30] pointed out that for POWS especially the defect concentration is a critical parameter, because the relatively slow water splitting reaction has to compete with the high recombination rate in defect-rich materials. A high degree of crystallinity is often required rather than a high surface area, because recombination between photogenerated electrons and holes is a serious problem for thermodynamic uphill reactions like POWS. In contrast, a high surface area is necessary for the photocatalytic degradation of organic compounds, because the adsorption of the organic compounds is an important process. Moreover, Domen et al. reported that although the water oxidation rate is scaling with the surface area, the hydrogen evolution, which depends predominantly on the structural properties of the sample, is the ratedetermining step [31]. After a nitridation time of $5 \mathrm{~h}$, the $\left(\mathrm{Ga}_{1-\mathrm{x}} \mathrm{Zn}_{\mathrm{x}}\right)\left(\mathrm{N}_{1-\mathrm{x}} \mathrm{O}_{\mathrm{x}}\right)$ sample shows little microstrain and low fault densities (Figure 5). Although the $\mathrm{Zn}$ content is considerably lower as in the starting material before nitridation, there is still a significant amount left $(x=0.06)$, resulting in a band gap of $2.55 \mathrm{eV}$ and the specific surface area is still reasonably large $\left(17 \mathrm{~m}^{2} / \mathrm{g}\right)$. Therefore, we regarded the sample after $5 \mathrm{~h}$ nitridation as one of the most promising for photocatalytic applications. The parameters responsible for creating an active material are very sensitive. Either very short or very long nitridation times do not result in high activity. No activity at all was observed when a light source with visible light (Xe lamp) was applied.

The problem with low/varying photocatalytic activities of $\left(\mathrm{Ga}_{1-\mathrm{x}} \mathrm{Zn}_{\mathrm{x}}\right)$ $\left(\mathrm{N}_{1-\mathrm{x}} \mathrm{O}_{\mathrm{x}}\right)$-based materials with appropriate visible light absorbing properties is also reported by Hensen et al. [32] and discussed in detail. It is concluded that 
large differences in activity are the result of small differences in the surface composition, which in turn is affected by the tight control of the synthesis of the oxynitride. Also the contact with the co-catalyst and the oxidation state of the $\mathrm{Rh}$ particles, which is size-dependent, affects the final performance through the effectiveness of electron extraction from the conduction band. In this respect, $\mathrm{Rh}$ oxide is less efficient than Rh metal.

EDS maps display the local element distribution in nanoparticles and are used to monitor the homogeneity of the co-catalysts (Figure 11). The nominal Rh loading of 0.3 wt.\% equals to a $\mathrm{Rh} /(\mathrm{Ga}+\mathrm{Zn})$ ratio of 0.27 as observed by EDS. The nominal Cr loading of $0.1 \mathrm{wt} . \%$ is below the EDS detection limit. After noise reduction of the EDS spectrum imaging by multivariate analysis [33], the $\mathrm{Rh}-\mathrm{L}$ peak is visible whereas the $\mathrm{Cr}-\mathrm{K}$ peak is not present. Table 2 lists the average $\mathrm{Rh} /(\mathrm{Ga}+\mathrm{Zn})$ ratios for three EDS mappings performed on single particles. These are significantly higher than the nominal value, which can be explained by a variation of

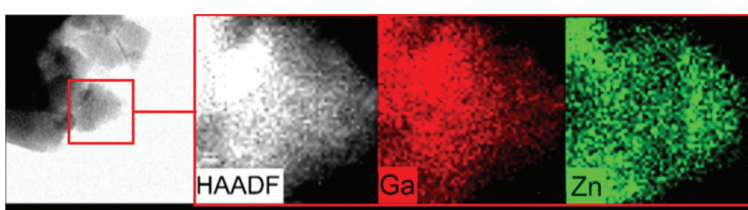

$50 \mathrm{~nm}$

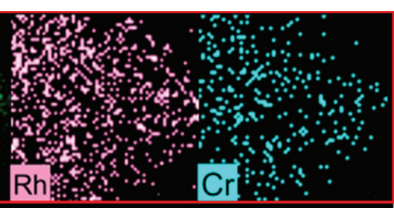

$7 \mathrm{~nm}$

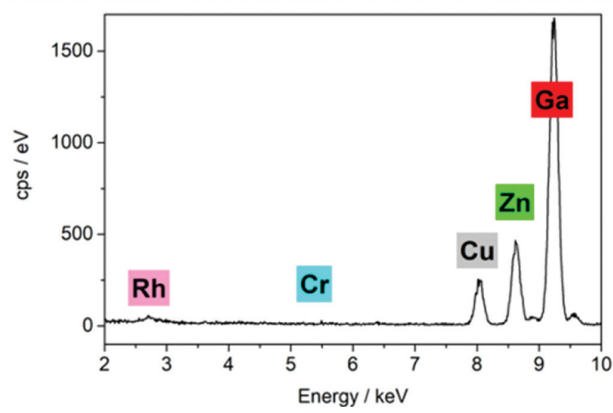

Fig. 11: Elemental distribution for $\left(\mathrm{Ga}_{1-x} \mathrm{Zn}_{\mathrm{x}}\right)\left(\mathrm{N}_{1-x} \mathrm{O}_{\mathrm{x}}\right)$ nitrided for 5 h by EDS/TEM after a typical photocatalytic water splitting activity experiment including photodeposition of $\mathrm{Cr}$ and Rh.

Tab. 2: Local distribution of Rh observed in EDS maps.

\begin{tabular}{rrrrrr}
\hline & Nominal composition & EDS 1 & EDS 2 & EDS 3 & EDS average \\
\hline $\mathrm{Rh} /(\mathrm{Ga}+\mathrm{Zn})(\%)$ & $\mathbf{0 . 2 7}$ & 0.89 & 0.83 & 1.15 & $\mathbf{0 . 9 5}$ \\
\hline
\end{tabular}


the local concentration. $\mathrm{Rh}$ is a much heavier element than $\mathrm{Ga}$ and $\mathrm{Zn}$ and should stand out according to the atomic number contrast in the HAADF-STEM image. We observed subnanometer bright features, which can be attributed to small $\mathrm{Rh}$ atomic clusters. However, the bright features move on the surface of the nanoparticles, which may explain why $\mathrm{Rh}$ is observed uniformly in the elemental map. We did not observe any $\mathrm{CrO}_{\mathrm{x}}$ nanoparticles larger than $1 \mathrm{~nm}$. In conclusion, we can state that the co-catalyst is present in a fairly dispersed condition.

\subsubsection{Comparison of the POWS activities of the nitrided samples and the CVS prepared $\mathrm{Ga}_{2} \mathrm{O}_{3}-\mathrm{ZnO}$ mixture}

Photocatalytic activities of the samples with optimal co-catalyst loadings of $0.1 \mathrm{wt} . \% \mathrm{Cr}$ and $0.3 \mathrm{wt} . \% \mathrm{Rh}$ were recalculated per gram of catalyst only for comparison. In Figure 12 the photocatalytic activity of the sample nitrided for $5 \mathrm{~h}$ shows the highest activity for POWS among the nitrided samples. Compared with the corresponding starting oxide it shows lower POWS activity. The reason could be the change from the direct to the indirect band gap as well as the intrinsic properties of the oxides vs. oxynitrides. However, because of the very low defect density (i.e. high crystallinity) the photocatalytic activity of the sample nitrided for $5 \mathrm{~h}$ approaches the activity of the CVS-prepared $\mathrm{Ga}_{2} \mathrm{O}_{3}-\mathrm{ZnO}$. The estimated quantum

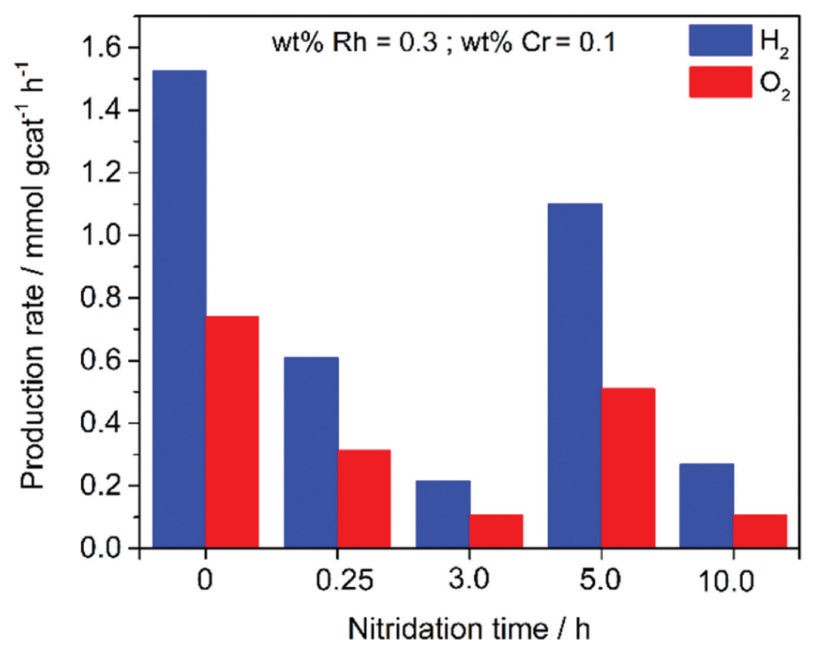

Fig. 12: Comparison of POWS activity with optimal loading of 0.1 wt.\% $\mathrm{Cr}$ and 0.3 wt.\% of Rh recalculated per gram of catalyst for the CVS-prepared $\mathrm{Ga}_{2} \mathrm{O}_{3}-\mathrm{ZnO}$ mixture before and after various nitridation times. 
yields amount to $2.1 \%$ for the $\mathrm{Ga}_{2} \mathrm{O}_{3}-\mathrm{ZnO}$ mixture (for comparison, the value for commercial $\mathrm{Ga}_{2} \mathrm{O}_{3}$ from Chempur was determined to be approximately $20 \%$ using the same setup) and $0.2 \%$ for the sample nitrided for $5 \mathrm{~h}$. By substituting $\mathrm{Ga}^{3+}$ with $\mathrm{Zn}^{2+}$ in an active material like $\mathrm{Ga}_{2} \mathrm{O}_{3}$ to make it absorb visible light we create the intermediate states in the band gap and those can act as recombination centres (traps) and therefore it expected that the activity of the material decreases. The latter value is lower than values reported by Domen and coworkers, who used even light with wavelengths between 400 and $500 \mathrm{~nm}$. Interestingly, the relative activity in the presence of methanol as a hole acceptor compared with the activity in the absence of methanol is quite high for the CVS-prepared $\mathrm{Ga}_{2} \mathrm{O}_{3}-\mathrm{ZnO}$ mixture (factor $\sim 10$ ), but low for the oxynitride (factor $\sim 2$ ). This observation indicates that in case of the oxynitride the overall reaction is not so much controlled by the water oxidation rate.

\section{Conclusions}

In a first step chemical vapor synthesis is performed to produce homogeneous $\mathrm{ZnO}-\mathrm{Ga}_{2} \mathrm{O}_{3}$ nanoparticle mixtures at high temperatures (1200 and $\left.1000{ }^{\circ} \mathrm{C}\right)$. Powders synthesized from the gas phase exhibit higher crystallinity and higher specific surface areas compared to materials obtained by conventional synthesis methods. In a second step the parent $\mathrm{ZnO}-\mathrm{Ga}_{2} \mathrm{O}_{3}$ nanoparticle mixtures were nitrided under a flow of ammonia for $0.17 \mathrm{~h}$ to $10 \mathrm{~h}$ to obtain the desired $\left(\mathrm{Ga}_{1-\mathrm{x}} \mathrm{Zn}_{\mathrm{x}}\right)\left(\mathrm{N}_{1-\mathrm{x}} \mathrm{O}_{\mathrm{x}}\right)$ wurtzite phase. We investigated the influence of the nitridation time on the microstructure of the materials and their photocatalytic activity. We are able to create very well-defined materials with low defect densities. After $5 \mathrm{~h}$ of nitridation the material still displayed a sufficiently large specific surface area combined with a $\mathrm{Zn} /(\mathrm{Zn}+\mathrm{Ga})$ ratio of 0.06 and an indirect band gap energy of $2.55 \mathrm{eV}$ leading to the highest photocatalytic activity of all nitrided samples investigated. In general, photocatalysis favours semiconductors with DBG, while the efficiency decreases for semiconductors with IBG. In general, shorter nitridation times leed to higher contents of $\mathrm{Zn}$ in the $\left(\mathrm{Ga}_{1-\mathrm{x}} \mathrm{Zn}_{\mathrm{x}}\right)\left(\mathrm{N}_{1-\mathrm{x}} \mathrm{O}_{\mathrm{x}}\right)$ material, which lowers the band gap, making the material suitable for absorption of visible light. With longer nitridations high crystallinity and low defect density are observed and supposed to have a positive effect on the POWS activity. The optimum nitridation time in this work is $5 \mathrm{~h}$.

Acknowledgment: The authors would like to thank Dr. Markus Heidelmann from the Interdisciplinary Center for Analytics on the Nanoscale (ICAN) at University of Duisburg-Essen for one part of the TEM analysis. We gratefully acknowledge 
the financial support by the Deutsche Forschungsgemeinschaft (DFG) within the Priority Program SPP 1613 project. We also greatly appreciate the close collaboration within the Priority Program SPP 1613.

\section{References}

1. K. Maeda, J. Photochem. Photobiol. C Photochem. Rev. 12 (2011) 241.

2. K. Maeda, K. Domen, J. Phys. Chem. C 111 (2007) 7851.

3. Y. Lee, H. Terashima, Y. Shimodaira, K. Teramura, M. Hara, H. Kobayashi, K. Domen, M. Yashima, J. Phys. Chem. C 111 (2007) 1042.

4. K. Maeda, K. Teramura, D. Lu, T. Takata, N. Saito, Y. Inoue, K. Domen, Nature 440 (2006) 295.

5. T. Ohno, L. Bai, T. Hisatomi, K. Maeda, K. Domen, J. Am. Chem. Soc. 134 (2012) 8254.

6. T. Hisatomi, K. Maeda, D. Lu, K. Domen, ChemSusChem 2 (2009) 336.

7. X. Sun, K. Maeda, M. Le Faucheur, K. Teramura, K. Domen, Appl. Catal. A 327 (2007) 114.

8. K. Maeda, K. Domen, Chem. Mater. 22 (2009) 612.

9. K. Maeda, PCCP 15 (2013) 10537.

10. L. L. Jensen, J. T. Muckerman, M. Newton, J. Phys. Chem. C 112 (2008) 3439.

11. H. Jansen, J. Menze, M. Muhler, ZAAC 644 (2018) 1686.

12. H. Chen, W. Wen, Q. Wang, J. C. Hanson, J. T. Muckerman, E. Fujita, A. I. Frenkel, J. Rodriguez, J. Phys. Chem. C 113 (2009) 3650.

13. S. Lukic, J. Menze, P. Weide, G. W. Busser, M. Winterer, M. Muhler, ChemSusChem 10 (2017) 4190.

14. Y. Nakibli, Y. Mazal, Y. Dubi, M. Waøchtler, L. Amirav, Nano Lett. 18 (2018) 357.

15. N. C. Popa, J. Appl. Cryst. 31 (1998) 180.

16. E. B. Warren, X-ray Diffraction, Courier Corporation (1990).

17. G. W. Busser, B. Mei, M. Muhler, ChemSusChem 5 (2012) 2200.

18. S.-H. Wei, A. Zunger, Phys. Rev. B 37 (1988) 8958.

19. K. Maeda, T. Takata, M. Hara, N. Saito, Y. Inoue, H. Kobayashi, K. Domen, J. Am. Chem. Soc. 127 (2005) 8286.

20. K. Maeda, K. Teramura, T. Takata, M. Hara, N. Saito, K. Toda, Y. Inoue, H. Kobayashi, K. Domen, J. Phys. Chem. B 109 (2005) 20504.

21. A. Leineweber, Z. Kristallogr. 226 (2011) 905.

22. D. P. Chen, Y. Losovyj, S. E. Skrabalak, J. Phys. Chem. C 122 (2017) 13250.

23. P. M. Diehm, P. Ágoston, K. Albe, Chem. Phys. Chem. 13 (2012) 2443.

24. W. Paszkowicz, S. Podsiadło, R. Minikayev, J. Alloys Compd. 382 (2004) 100.

25. T. Hirai, K. Maeda, M. Yoshida, J. Kubota, S. Ikeda, M. Matsumura, K. Domen, J. Phys. Chem. C 111 (2007) 18853.

26. D. Z. Kong, Y, M. Kobielusz, Y. Wang, Z. Bai, W. Macyk, X. Wang, J. Tang, Mater. Today 21 (2018) 897.

27. K. Maeda, K. Teramura, N. Saito, Y. Inoue, K. Domen, J. Catal. 243 (2006) 303.

28. K. Maeda, K. Teramura, D. Lu, N. Saito, Y. Inoue, K. Domen, Angew. Chem. Int. Ed. 118 (2006) 7970.

29. J. Soldat, G. W. Busser, M. Muhler, M. Wark, ChemCatChem 8 (2016) 153. 
30. A. Kudo, Y. Miseki, Chem. Soc. Rev. 38 (2009) 253.

31. K. Maeda, H. Hashiguchi, H. Masuda, R. Abe, K. Domen, J. Phys. Chem. C 112 (2008) 3447.

32. Y. Zhang, M. Ligthart, P. Liu, L. Gao, T. Verhoeven, E. Hensen, Chin. J. Catal. 35 (2014) 1944.

33. S. Zhang, C. Scheu, Microscopy 67 (2018) i133. 